lead to better understanding of the current concepts about atrial fibrillation.

\section{References}

1. Benussi S, Pappone C, Nascimbene S, et al. A simple way to treat atrial fibrillation during mitral valve surgery: the epicardial radiofrequency approach. Eur J Cardiothorac Surg. 2000;17:524-9.

2. Cox JL, Canavan T, Jaquiss RD, et al. The surgical treatment of atrial fibrillation. II. Intraoperative electrophysiologic mapping and description of the electrophysiologic basis of atrial flutter and atrial fibrillation. J Thorac Cardiovasc Surg. 1991;101:406-26.

3. Garrey WE. Auricular fibrillation. Physiol Rev. 1924;4:215-50.

4. Haissaguerre M, Jais P, Shah DC, et al. Spontaneous initiation of atrial fibrillation by ectopic beats originating in the pulmonary veins. $N$ Engl J Med. 1998;339:659-66.

5. Melo JQ, Adragão P, Neves J, et al. Surgery for atrial fibrillation using intra-operative radiofrequency ablation. Rev Port Cardiol. 1998;17: $377-9$.

\title{
Combined repair of an aortic arch aneurysm by sequential transposition of the supra-aortic branches and endovascular stent-graft placement
}

\author{
Martin Czerny, MD, Tatjana Fleck, MD, Daniel Zimpfer, MS, Juliane Kilo, MD, Dominique Sandner, RT, \\ Manfred Cejna, MD, Johannes Lammer, MD, Ernst Wolner, MD, and Martin Grabenwoger, MD, Vienna, Austria
}

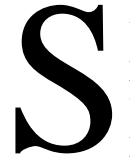

urgical repair of aortic arch aneurysms still is an invasive procedure requiring arch replacement during deep hypothermic circulatory arrest. ${ }^{1,2}$ Endovascular stent-graft placement is a safe and effective treatment modality in various diseases of the descending aorta. ${ }^{3-7}$ However, if supraaortic branches are involved, the application of endovascular stentgraft placement requires sophisticated surgical approaches to maintain cerebral perfusion. ${ }^{8-11} \mathrm{We}$ report an 80 -year-old man who had a contained rupture of an aortic arch aneurysm involving the origin of the left carotid artery. The patient was treated by sequential transposition of the left carotid artery into the brachiocephalic trunk and the left subclavian artery into the previously transposed left common carotid artery, with subsequent endovascular stent-graft placement into the aortic arch.

\section{Clinical Summary}

An 80-year-old man was admitted to our department with a contained rupture of an aortic arch aneurysm. A preoperative 3-dimensional computed tomography (CT) scan revealed that the aneurysm had a maximum diameter of $8 \mathrm{~cm}$ (Figure $1, A$ ). In the operating room, a median sternotomy was performed and the pericardium opened. We found a hemorrhagic pericardial effusion,

\footnotetext{
From the Departments of Cardiothoracic Surgery and Interventional Radiology, University of Vienna Medical School, Vienna, Austria.

Received for publication Dec 5, 2002; accepted for publication Dec 27, 2002.

Address for reprints: Dr Martin Czerny, Waehringer Guertel 18-20, A-1090, Vienna, Austria, Europe (E-mail: bypass@eunet.at).

J Thorac Cardiovasc Surg 2003;126:916-8

Copyright $\odot 2003$ by The American Association for Thoracic Surgery $0022-5223 / 2003 \$ 30.00+0$

doi:10.1016/S0022-5223(03)00222-8
}

indicating the development of a retrograde hematoma within the ascending aorta. To keep the procedure as minimally invasive as possible, the concavity of the aortic arch was sealed with local hemostyptic agents. After systemic heparinization with $5000 \mathrm{IU}$, the left common carotid artery was dissected free and clamped. The vessel was divided transversely. The proximal portion was closed with a 4-0 Prolene running suture (Ethicon, Inc, Somerville, $\mathrm{NJ}$ ). At the next step, the brachiocephalic trunk was partially clamped and longitudinally opened, and a side-to-end anastomosis was performed. After flushing and deaeration, blood flow was restored. A similar procedure was performed between the left subclavian artery and the previously transposed left common carotid artery. A chest tube was inserted and the wound was closed in layers. The patient recovered uneventfully without any signs of neurologic injury.

The next day the patient was taken to the interventional radiologists' suite. General anesthesia was administered and the common femoral artery was dissected free. A 5F-calibrated angiographic pigtail catheter was advanced via the right brachial artery into the aortic arch to reconfirm the morphology and extent of the aneurysm (Figure 1, B). After systemic heparinization with 5000 IU, a common femoral artery arteriotomy was performed and the delivery system was advanced under fluoroscopic guidance until the tip reached the origin of the brachiocephalic trunk. Thereafter, 3 Talent stent grafts (Medtronic, Sunrise, Fla) were inserted into the aortic arch. The stent grafts were deployed by quick withdrawal of the outer sheath while the pusher mandrel was held firmly. At the final angiography, a small type 1 endoleak was observed. The procedure was discontinued and the endoleak was monitored. After 1 week the patient was readmitted for the final 3-dimensional CT scan and angiography. Interestingly, the leak had occluded spontaneously (Figure 2, $A$ and $B$ ).

\section{Comment}

This is the first clinical report of a combined sequential autologous transposition of the left common carotid artery into the brachio- 

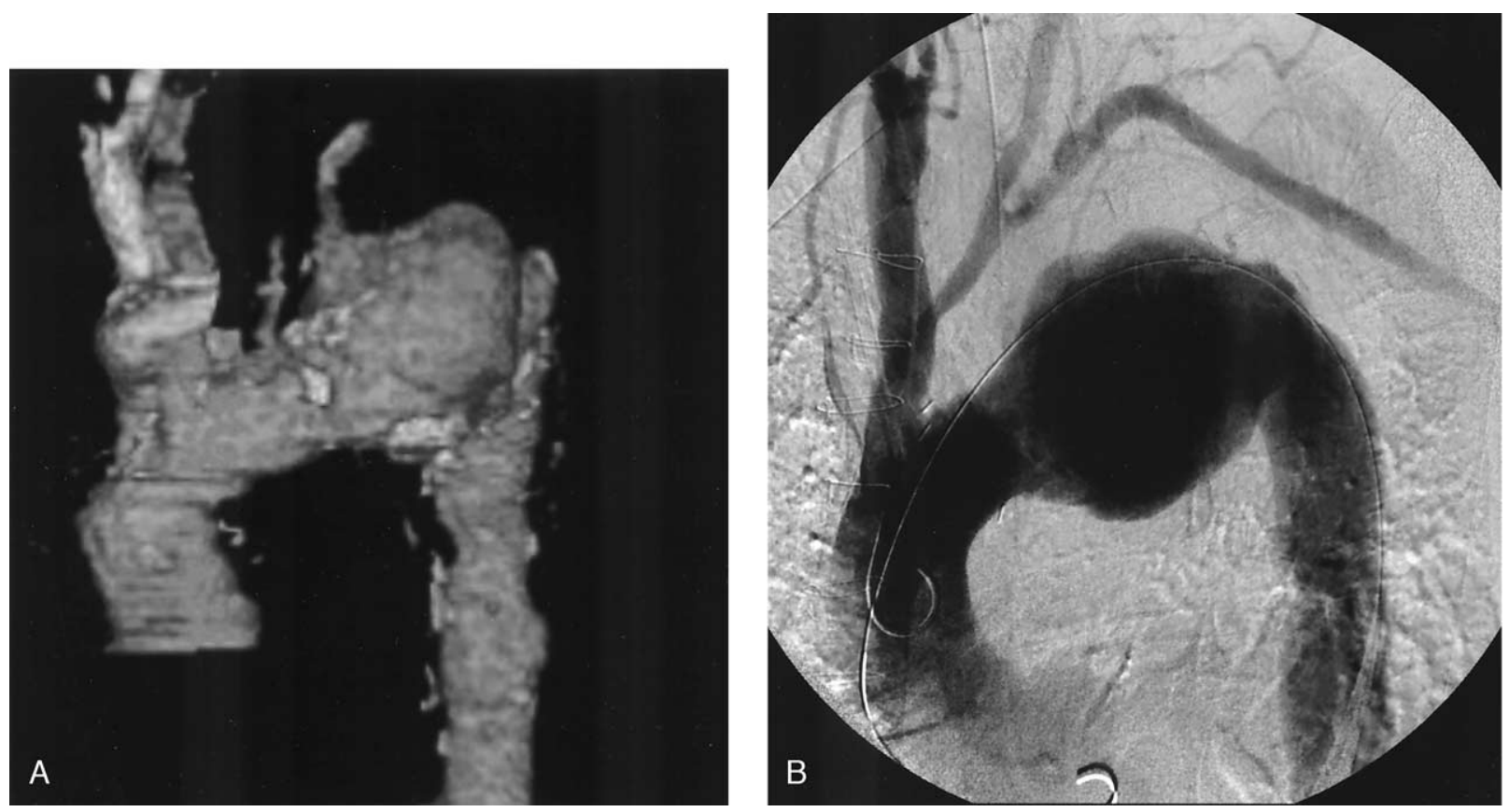

Figure 1. A, Preoperative CT scan. B, Postoperative angiogram, after transposition, before stent-graft placement.
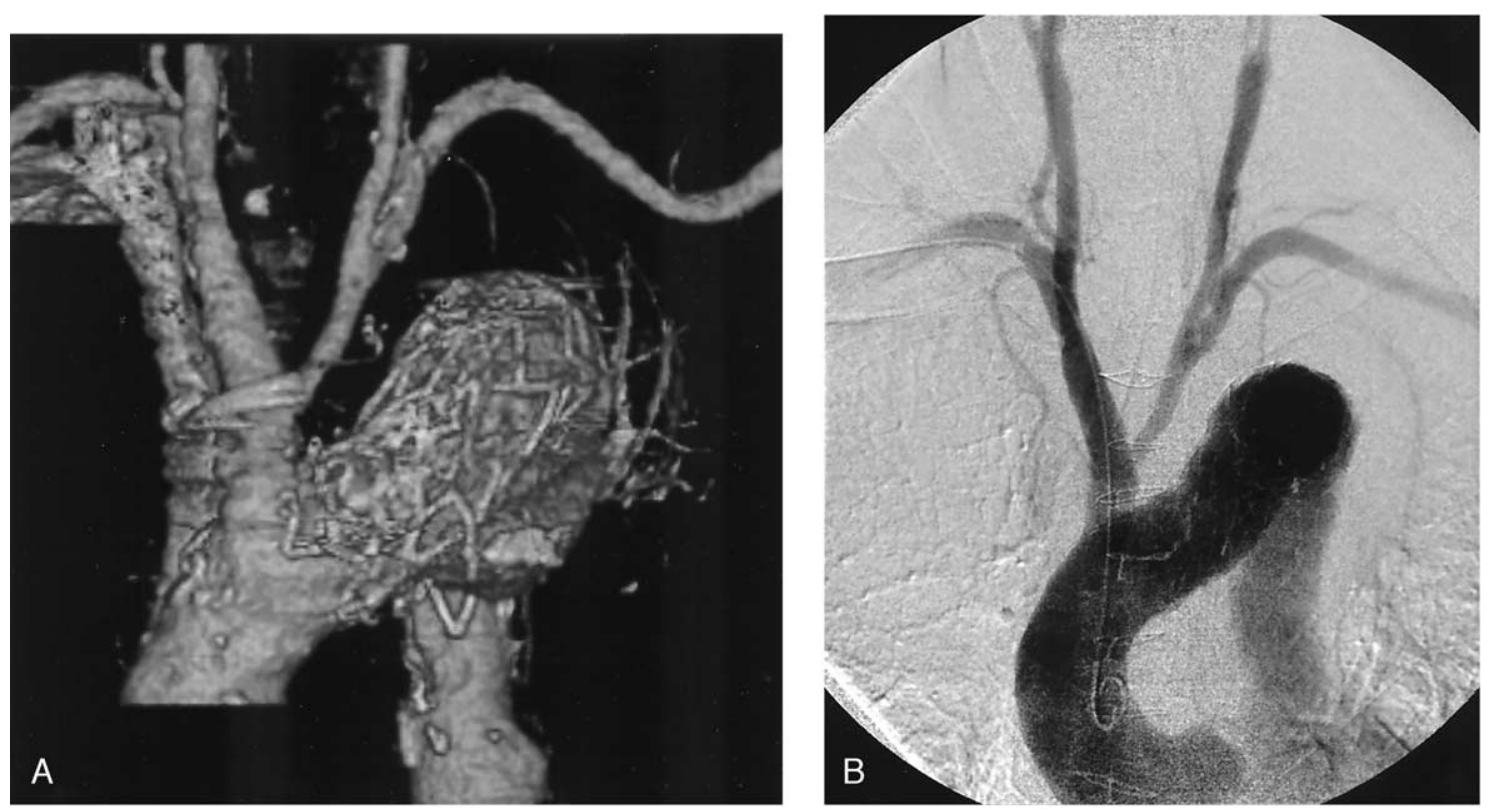

Figure 2. A, CT scan after stent-graft placement. B, Postoperative angiogram, after stent-graft placement.

cephalic trunk, as well as the left subclavian artery into the previously transposed common carotid artery, with subsequent stent-graft placement to treat a contained rupture of an aortic arch aneurysm.

The main advantage of this approach, besides the fact that the procedure is not very invasive, is the avoidance of alloplastic material to maintain perfusion of the arch vessels. Alloplastic replacement of native blood vessels always bears the risk of infection and its potential adverse consequences. ${ }^{12}$ In contrast, this vascular surgical approach elegantly maintains supra-aortic perfusion by effecting a standard arterial transposition between the left subclavian and the left common carotid artery to the brachiocephalic trunk. Additionally, the potential risk of clots on the artificial surface of an alloplastic vascular prosthesis is avoided. Inter- 
estingly, neither infection nor clots have been reported to date in thoracic aortic endovascular stent grafts.

As this article presents our initial experience with autologous sequential transposition and stent-graft placement, no statements can currently be made about the long-term outcome of the procedure. Several technical aspects have to be considered. The formation of type 1 endoleaks in this highly shear-stress-exposed area must be closely monitored. Additionally, because of the very curved pathway in this anatomic location, a backbone fracture of the stent graft must be kept in mind. Nevertheless, combined approaches for arch aneurysms will extend the applicability of the procedure in this delicate anatomic region. In fact, a variety of adjunctive techniques of stent-graft placement in patients with arch aneurysms are currently available. ${ }^{8-11}$ These techniques will allow safe and effective treatment of this highly select subgroup of patients with aortic aneurysms by avoiding conventional arch aneurysm repair in deep hypothermia and circulatory arrest.

\section{References}

1. Kazui T, Washiyama N, Muhammad BA, Terada H, Yamashita K, Takinami M. Improved results of atherosclerotic arch aneurysm operations with a refined technique. J Thorac Cardiovasc Surg. 2001;121: 491-9.

2. Westaby S, Katsumata T. Proximal aortic perfusion for complex arch and descending aortic disease. J Thorac Cardiovasc Surg. 1998;115: 162-7.

3. Dake MD, Kato N, Mitchell RS, et al. Endovascular stent-graft place- ment for the treatment of acute aortic dissection. $N$ Engl $J$ Med. 1999;340:1546-52.

4. Nienaber CA, Fattori R, Lund G, et al. Nonsurgical reconstruction of thoracic aortic dissection by stent-graft placement. $N$ Engl J Med. 1999;340:1539-45.

5. Dake MD, Miller DC, Semba CP, Mitchell RS, Walker PJ, Liddell RP. Transluminal placement of endovascular stent-grafts for the treatment of descending thoracic aortic aneurysms. N Engl J Med. 1994;331: 1729-34.

6. Hutschala D, Fleck T, Czerny M, et al. Endoluminal stent-graft placement in patients with acute aortic dissection type B. Eur J Cardiothorac Surg. 2002;21:964-9.

7. Schoder M, Grabenwoger M, Holzenbein T, et al. Endovascular stentgraft repair of complicated penetrating atherosclerotic ulcers of the descending thoracic aorta. J Vasc Surg. 2002;36:720-6.

8. Criado FJ, Barnatan MF, Rizk Y, Clark NS, Wang C. Technical strategies to expand stent-graft applicability in the aortic arch and proximal descending thoracic aorta. J Endovasc Ther. 2002;9:II328.

9. Buth J, Penn O, Tielbeek A, Mersman M. Combined approach to stent-graft treatment of an aortic arch aneurysm. J Endovasc Surg. 1998;5:329-32.

10. Iguro Y, Arata K, Yamamoto H, Masuda H, Sakata R. A new concept in distal arch aneurysm repair with a stent graft. $J$ Thorac Cardiovasc Surg. 2002;123:378-80.

11. Okada K, Sueda T, Orihashi K, Watari M, Ishii O. An alternative procedure of endovascular stent-graft repair for distal arch aortic aneurysm involving arch vessels. J Thorac Cardiovasc Surg. 2001; 121:182-4.

12. Vogt PR, Brunner-La Rocca HP, Carrel T, et al. Cryopreserved vascular allograft in the treatment of major vascular infection: a comparison with conventional surgical techniques. J Thorac Cardiovasc Surg. 1998;116:965-72.

\title{
Controlled exsanguination during sternal reentry
}

\author{
Alejandro Aris, MD, PhD, Barcelona, Spain
}

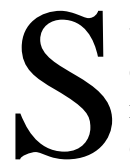

ternal reentry can cause catastrophic hemorrhage. Several maneuvers have been advocated to reduce this risk. $^{1-4}$ The new simple method of heart decompression during sternal reentry described here is based on controlled exsanguination ( $1500 \mathrm{~mL}$ of blood) through a long venous cannula before sternal opening, with rapid retransfusion through the same cannula. This technique avoids femoral artery cannulation.

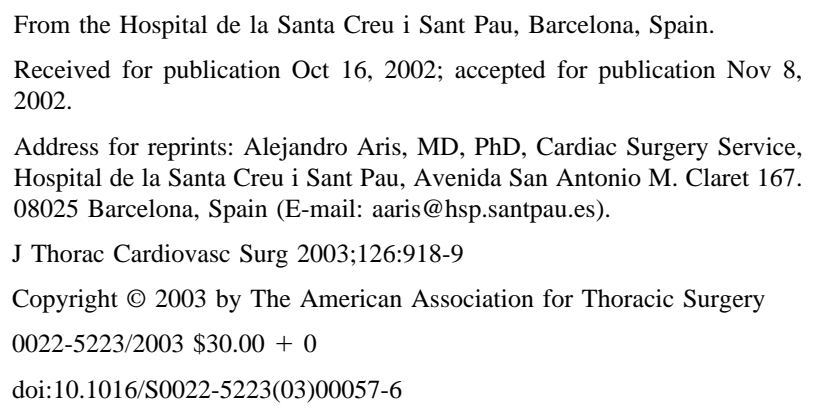

\section{Patients and Methods}

Patient data. Twelve patients underwent reoperation with this technique at my institution. All were subjected to valvular reoperations. Surgical procedures included 4 mitral

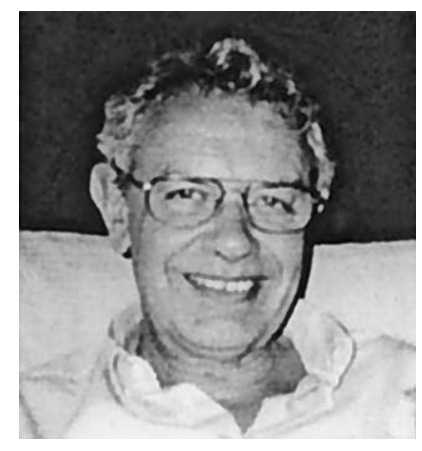

Alejandro Aris, MD, PhD valve replacements combined with tricuspid annuloplasty, 3 aortic valve replacements (2 with tricuspid annuloplasty), 1 tricuspid valve replacement, 2 repairs of a mitral periprosthetic leak, 1 mitral valve rereplacement because of pannus formation, and 1 double valve replacement for prosthetic endocarditis. It was the third operation for 1 patient and the fourth for another.

Surgical technique. After the skin was opened, the sternal wires were untwisted. The femoral vessels were exposed through a small groin incision. After complete heparinization, a long (50 cm) 28F cannula (DLP 96328; Medtronic, Inc, Minneapolis, Minn) was introduced into the vein by the Seldinger technique, and its tip was advanced up to the level of the right atrium. The cannula was connected to the venous line of the extracorporeal circuit and to the 